\title{
Buckling Response of a Large-Scale, Seamless, Orthogrid- Stiffened Metallic Cylinder
}

\author{
Michelle Tillotson Rudd ${ }^{1}$ \\ NASA Marshall Space Flight Center, Huntsville, AL, 35812 \\ Mark W. Hilburger ${ }^{2}$, Andrew E. Lovejoy ${ }^{3}$, Michael C. Lindell ${ }^{4}$ \\ NASA Langley Research Center, Hampton, VA, 23681 \\ Nathaniel W. Gardner ${ }^{5}$ \\ Analytical Services and Materials, Inc., Hampton, VA, 23666 \\ and \\ Marc R. Schultz 6 \\ NASA Langley Research Center, Hampton, VA, 23681
}

\begin{abstract}
Results from the buckling test of a compression-loaded 8-ft-diameter seamless (i.e., without manufacturing joints), orthogrid-stiffened metallic cylinder are presented. This test was used to assess the buckling response and imperfection sensitivity characteristics of a seamless cylinder. In addition, the test article and test served as a technology demonstration to show the application of the flow forming manufacturing process to build more efficient bucklingcritical structures by eliminating the welded joints that are traditionally used in the manufacturing of large metallic barrels. Pretest predictions of the cylinder buckling response were obtained using a finite-element model that included measured geometric imperfections. The buckling load predicted using this model was $697,000 \mathrm{lb}$, and the test article buckled at $743,000 \mathrm{lb}(6 \%$ higher). After the test, the model was revised to account for measured variations in skin and stiffener geometry, nonuniform loading, and material properties. The revised model predicted a buckling load of 754,000 $\mathrm{lb}$, which is within $1.5 \%$ of the tested buckling load. In addition, it was determined that the load carrying capability of the seamless cylinder is approximately $\mathbf{2 8 \%}$ greater than a corresponding cylinder with welded joints.
\end{abstract}

\section{Nomenclature}

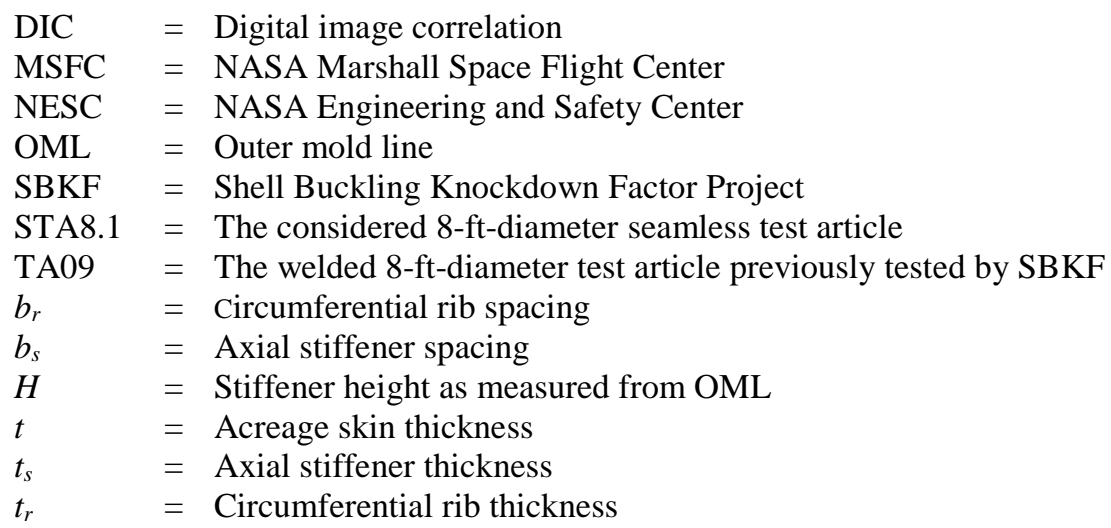

\footnotetext{
${ }^{1}$ Aerospace Engineer, Dynamics, Loads \& Strength Branch, EV31, Member AIAA.

${ }^{2}$ Senior Research Engineer, Structural Mechanics \& Concepts Branch, MS 190, Senior Member AIAA.

${ }^{3}$ Research Aerospace Engineer, Structural Mechanics \& Concepts Branch, MS 190, Associate Fellow AIAA.

${ }^{4}$ Senior Structural Analyst, Structural and Thermal Systems Branch, MS 431, AIAA Senior Member

${ }^{5}$ Senior Scientist, supporting the Structural Mechanics \& Concepts Branch, MS 190.

${ }^{6}$ Research Aerospace Engineer, Structural Mechanics \& Concepts Branch, MS 190, Senior Member AIAA.
} 
$t_{t} \quad=$ Transition region thickness

$t_{w} \quad=$ Weld land or end thickness

\section{Introduction}

The NASA Engineering Safety Center (NESC) Shell Buckling Knockdown Factor Project (SBKF) was established $\mathbf{I}$ in 2007 with the primary objective to develop new analysis-based buckling design factors and guidelines for metallic and composite launch-vehicle structures. ${ }^{1}$ A secondary objective of the project is to advance technologies that have the potential to increase the structural efficiency of launch vehicles, for example, by eliminating axial welded joints in metallic structures.

Traditionally, large-scale metallic launch-vehicle stiffened cylindrical structures are fabricated by joining several curved panel sections together to form a complete cylinder. Welded joints in these types of structures typically include a relatively thick region, referred to as a weld land, on which the welding is performed. Previous studies by SBKF have determined that stiffness and geometric discontinuities associated with longitudinal weld lands in compressionloaded cylinders can reduce the buckling load of the cylinder. In addition, the welding process can introduce localized geometric imperfections that can further exacerbate the inherent buckling imperfection sensitivity of the cylinder. Thus, it is expected that seamless cylinder fabrication technologies can improve structural efficiency by eliminating these weld-related issues.

In order to investigate seamless manufacturing methods, SBKF partnered with the Advanced Materials and Processing Branch at NASA Langley Research Center, the Mechanical and Fabrication Branch at NASA Marshall Space Flight Center (MSFC), and ATI Forged Products, formerly ATI Ladish Forgings, to design and fabricate an 8ft-diameter orthogrid-stiffened seamless metallic cylinder for compression load testing. The purpose of this test effort was to demonstrate the potential benefits of building cylindrical structures with no weld lands using a flow-forming manufacturing process and to assess the buckling behavior of a seamless grid-stiffened metallic cylinder. To achieve this, the test article was subjected to seven subcritical load sequences (load sequences that are not intended to induce test-article buckling or material failure) and one load sequence to buckling failure.

It is expected that a seamless cylinder will exhibit different buckling behavior and imperfection sensitivity than cylinders with weld lands. To make this comparison, the results from the seamless grid-stiffened cylinder analysis will be compared to analysis results from an 8-ft-diameter test article with a similar acreage design that has weld lands. These behaviors need to be well understood if this type of seamless cylinder structure is to be implemented in future launch-vehicle concepts.

In Section II, the fabrication and design of the test article is discussed, along with a description of the test set up and test facilities. A description of the pretest prediction model, results from the test, and additional model refinements incorporated to better capture the behavior of the test article are given in Section III. The performance of the seamless grid-stiffened cylinder and a welded grid-stiffened cylinder is compared in Section IV, and concluding remarks are made in Section $\mathrm{V}$.

\section{Manufacturing and Testing Details}

The test article, herein referred to as STA8.1, was manufactured from an 8,000 pound Al 2219 ingot at ATI Ladish Forgings, now ATI Forged Products, using a flow-forming process to produce a cylinder with an outside diameter of 96.50 in., a length of 90 in., and a wall thickness of 2.5 inches. The cylinder was then heat treated to reach its final T851 condition. Material was removed from the forward and aft ends of the cylinder for material property testing, which confirmed that the flow-forming process produced material properties that were similar to Al 2219-T851 plate properties defined in the Metallic Materials Properties Development and Standardization (MMPDS) Handbook. ${ }^{2}$

The cylinder was shipped to MSFC where the outer mold line (OML) was machined to its final diameter of 96 inches. The orthogrid pattern was then machined into the inside surface of the cylinder using a 7-axis milling machine, as shown in Fig. 1. To perform stiffener machining, the cylinder was laid on its side and secured in place using a custom vacuum chuck. A typical orthogrid stiffener pattern and design variables are shown in Fig. 2. Since there were no weld lands, 145 longitudinal stiffeners were evenly spaced at 2.482-degrees around the circumference of the cylinder, $b_{s}$, and the circumferential ribs had an axial spacing of $5.064 \mathrm{in} ., b_{r}$. The longitudinal and circumferential stiffeners were designed to have the same nominal thickness of $0.065 \mathrm{in}$., $t_{s}$ and $t_{r}$. The as-designed stiffeners had a nominal height of $0.570 \mathrm{in}$., $H$, as measured from the OML, and the nominal skin thickness was 0.070 in., $t$. At the ends of the cylinder, the acreage tapered into a transition section, as depicted in Fig. 3. For STA8.1 the transition nominal thickness was defined as $0.135 \mathrm{in}$., $t_{t}$, and the nominal thickness of the ends were $0.200 \mathrm{in}, t_{w}$.

After the orthogrid pattern was machined, the cylinder ends were trimmed and machined flat and parallel to give a final length of $77.595 \mathrm{in}$. Next, the cylinder was bolted and potted into steel interface rings to facilitate assembly 
into the test fixture. Prior to being installed in the test fixture, the geometry of the cylinder OML was measured using a structured-light scanning technique to accurately map the as-machined surface profile. This OML geometry data was then used to calculate the initial geometric imperfection of the cylinder, which is defined as the deviation of the measured geometry from a best-fit circular cylinder. The geometric imperfection data is shown in Fig. 4. The cooler colors (blues) represent an inward imperfection from the barrel's best fit cylinder, and the warmer colors represent an outward imperfection from the barrel's best-fit cylinder. It is seen that the imperfections are relatively small with a maximum outward displacement of 0.56-in. and a minimum inward displacement of 0.37 -in, an amplitude that is approximately $0.2 \%$ of the test article's radius.

After the cylinder was structured-light scanned, it was highly instrumented with approximately 180 electricalresistance strain gages, 24 displacement sensors, and fiber-optic strain sensors. Low- and high-speed digital image correlation systems (DIC) were used to measure strain and displacement data.

Following the instrumentation placement, the cylinder was installed into a special-purpose test facility at MSFC. The test assembly (Fig. 5) was designed for the buckling of 8-ft-diameter cylinders subjected to combined axial compression, bending and internal pressure. ${ }^{3}$ The test assembly is a self-reacting load system composed of an upper and lower load spider, 16 load struts, upper and lower transition sections, the test-article assembly, and eight load lines. Each load line consists of a hydraulic cylinder, 4-in.-diameter loading rod, a load cell, and attachment hardware. The load lines can be controlled independently in load control or position control to apply uniform compression or tension, or combined axial and bending loads with a maximum load capability of 1,500,000 lb of axial compression force and $80,000 \mathrm{lb}$ of axial tension.

\section{Test and Analysis Correlation}

Prior to the test to failure, seven subcritical tests were completed which included three different axial load sequences and four different combined bending and compression load sequences. The subcritical tests helped to verify the FEM prior to the test to failure. The three axial load cases applied $20 \%, 40 \%$, and $60 \%$ of the predicted linear buckling load of the perfect cylinder to the test article. The four bending load cases combined $20 \%$ of the critical axial buckling load with $20 \%$ of the calculated critical buckling moment, with maximum compression directed over the $0^{0}$, $90^{\circ}, 180^{\circ}$, and $270^{\circ}$ directions. During the final test to failure, the test article was loaded in pure axial compression until global buckling was observed.

\section{A. Finite-Element Analysis}

Pretest predictions of the buckling response of the cylinder were obtained using the general-purpose finite-element analysis code, Abaqus 2016. ${ }^{4}$ The cylinder was modeled using S4R reduced-integration four-noded elements. The mesh density used in the analysis was based on previous experience modeling similar welded test articles. The interface rings were modeled using B31 elements to constrain the ends of the barrel, which are potted in the interface rings. The beam elements restricted the test article from expanding radially, but allowed it to shorten axially. To accurately model the load introduction into the test article, the entire test assembly was modeled using a combination of S4R shell elements and B31 beam elements (Fig. 6). The cylinder was loaded by applying point loads to the ends of the eight load lines in the model. The test assembly finite-element model contained 624,278 elements and 663,011 nodes.

The pretest prediction model was constructed using nominal geometry, as reported in Table 1, and included the measured initial geometric imperfections. As previously stated, material property testing was completed to verify the flow-forming manufacturing method produced comparable strengths and stiffness of Al 2219-T851 as defined in MMPDS. A compressive elastic modulus of $10.73 \times 10^{6} \mathrm{psi}$ was used in the FEM. This value was calculated by averaging the compressive moduli from all coupon specimens cut in the barrel's axial orientation.

For the subcritical load sequences, where buckling or material yielding is not expected, a geometric nonlinear static analysis was performed. For the final test to failure a geometric nonlinear static analysis was used to predict the response of the cylinder up to $90 \%$ of the linear eigenvalue buckling load. From there, a nonlinear transient analysis was performed up to the buckling event and into postbuckling range.

\section{B. Test-Analysis Correlation}

During the subcritical cases, the test results correlated well qualitatively with analysis, but indicated the barrel was stiffer than originally predicted. Figure 7 presents the radial displacement results from the pretest prediction model at $409,928 \mathrm{lb}$ (60\% of the predicted linear buckling load), and Fig. 8 presents the radial displacement results from the test at the same load. The deformed shape for both test and analysis are similar and have a very regular patterns, with 
a single half wave in the axial direction and 8 full waves in the circumferential direction. During the final test to failure, buckling occurred at 743,000 lb of axial compression, which was $6 \%$ higher than the pretest predicted buckling load of $697,000 \mathrm{lb}$, as seen in Fig 9. The predicted and measured incipient buckling radial displacements are shown in Figs. 10 and 11, respectively. These radial displacement plots reveal that the analysis accurately predicted the deformed shape at buckling, four axial half waves and twelve circumferential waves, and the radial displacement values have similar relative magnitudes. The deformed shape is indicative of the linear eigenmode for this acreage design.

It is difficult to determine where the buckling initiated from either the predicted or measured radial displacement. Examination of the STA8.1 high-speed DIC displacement data suggests that there are multiple dimples, between $0^{\circ}$ and $45^{\circ}$, present at the maximum load that may have simultaneously led to the global buckling event. For comparison, previously tested welded-metallic cylinders had buckling events that originated as a single inward dimple at one of the weld lands, and this dimple initiated the global buckling of the cylinder.

\section{Posttest Model Refinements}

As is seen in the load-end shortening curve from the final load sequence, Fig. 9, the test article was approximately $8 \%$ stiffer than predicted. After the test, several model refinements were made to improve the correlation. Specifically, the model was modified to include the average as-built material thickness, nonuniform loading, and inclusion of separate compression and tension moduli. Some of these refinements had more of an influence on the response than others, but ultimately all the refinements helped improve the correlation between the test and analysis data. The results from these refined models are presented in this section.

To further understand the stiffness discrepancy between the test article and the model, the as-built geometry was examined in greater detail. According to the computer aided design model, the nominal weight of the barrel should be $265 \mathrm{lb}$, but the test article was measured to be $300 \mathrm{lb}$. The as-designed pocket (skin) thickness was $0.070 \mathrm{in} . \pm 0.010$, but the inspection reports determined the as-built pocket thickness varied from $0.071 \mathrm{in}$. to $0.081 \mathrm{in}$. To determine the extent of the thickness variation in STA8.1, core samples were collected from 40 pocket locations around the barrel. The core samples revealed an average pocket thickness of 0.0753 in., which is $8 \%$ higher than the nominal value of 0.070-in. Additionally, stiffener thickness measurements showed an average thickness of 0.070-in., which is $7 \%$ higher than the nominal design value of 0.065 in \pm 0.010 . The transition region had a measured thickness of 0.139 -in, and the end region had a measured thickness of 0.206 in., both of which were $3 \%$ thicker than the as-designed values of $0.135 \mathrm{in} . \pm 0.010$ and $0.200 \mathrm{in.} \pm 0.010$, respectively. Table 1 summarizes the average as-built geometry dimensions used in the future model refinement studies.

The incorporation of the average as-built material thicknesses had a substantial effect on the predicted response, and increased the effective axial stiffness by $7 \%$ compared to the pretest prediction model with nominal geometry. This increase in stiffness predicted a new buckling load of 759,000 lb, only $1.5 \%$ from the tested load. The predicted radial displacements at incipient buckling from this refined analysis are presented in Fig. 12; while the displacement magnitudes change from the pretest predictions (Fig. 10), the deformed shape remains essentially unchanged. Though the as-built geometry is close to the specified tolerance of $\pm 0.010 \mathrm{in}$., these small variations had a significant influence on the buckling load.

It was also discovered that at failure all eight load lines had slightly different applied load levels. The nonuniform loading data indicated a slight bending moment, of approximately $0.2 \%$ of the critical bending moment, acting where the maximum compression was located at the $338^{\circ}$ circumferential position. This orientation was determined by calculating the location of the resultant load. This additional bending moment was included in the model containing the average as-built geometry and resulted in a buckling load of 754,000 lb. This additional moment reduced the load by $0.7 \%$, compared to the $759,000 \mathrm{lb}$ predicted from the model with pure compression loading. The predicted loadvs.-displacement response of the model containing as-built geometry and $0.2 \%$ of the critical moment is shown in Fig. 9 along with the measured response. The radial displacement plot, Fig. 13, shows that the linear eigenmode shape, as seen in the pretest and as-built geometry analysis, is still apparent. The variation may be attributed to the overall tolerance stack up of the test assembly. Also, the variation of load recorded by the load cells was within the tolerance of the load cell accuracy, but it is important to note the sensitivity of the structure.

Finally, according to MMPDS and moduli data collected as a part of this program, Al 2219-T851 has different moduli depending on if the material is in tension or compression. To understand the influence of this behavior, orthotropic material properties were defined and incorporated into the model having as-built geometry with uniform axial compression. Recognizing that for cylinders subjected to axial compression the circumference is primarily in a state of tension due to Poisson expansion, and the axial direction is primarily in compression. The orthotropic properties used a compression modulus axially and a tension modulus circumferentially. A compression modulus of $10.73 \times 10^{6} \mathrm{psi}$ in the axial direction, and a tension modulus of $10.43 \times 10^{6} \mathrm{psi}(3.7 \%$ less than the compression 
modulus) in the circumferential direction. The tensile modulus was determined by averaging the tensile moduli in the circumferential direction from the material property testing. The separate compression and tension moduli were incorporated into the model with as-built geometry and uniform loading. The orthotropic material properties maintained the same effective axial stiffness, but decreased the predicted buckling load by $1 \%$ from 759,000 lb to $751,000 \mathrm{lb}$. This detail did predict a buckling load closer to the tested value of 743,000 lb. The predicted radial displacements from the analysis with the orthotropic properties are shown in Fig. 14.

It is important to note that while this material adjustment better reflects the global behavior of the test article by determining a buckling load closer to the tested value, it does not improve accuracy of the model in all cases. For example, when comparing the axial and hoop strain test data with the model including orthotropic material properties, it cannot be stated conclusively that the incorporation of tension and compression moduli is the best way to model this failure mode. In some cases this modification did help the model data align with test data, but not for all gage locations. To make this comparison, only strain gage locations where the measured pocket thicknesses were close to what was modeled, 0.00753 in., were investigated. This eliminated the potential for material thickness variability to impact the comparison.

Though there is very good correlation between test and analysis, there are some slight differences. To start, STA8.1 is approximately $2 \%$ stiffer than the models containing the average as-built geometry in uniform compression. While many realistic details were included in the finite-element model, the fillets between the skin and stiffeners were not. It has been demonstrated that the fillets can increase the overall stiffness of the test artcle. ${ }^{5}$ In addition, an average pocket thickness was assumed to be uniform throughout the test article. Based on inspection data and the 40 core samples taken of barrel skin, it is known that the pocket thickness varied from $0.0071 \mathrm{in}$. to $0.0081 \mathrm{in}$. If a larger sampling was taken, this could change the average thickness. The discrepancies in the FEM radial displacements and the tested radial displacements may be explained by the pocket thickness variation in the test article. Additionally, it was shown that the slightest nonuniform applied loading can have an effect on the buckling behavior as a result of the induced bending moment. Also, it should be noted that another detail relating to nonuniform loading, the potential effect from variations in interface ring flatness, was not investigated in this paper.

\section{Numerical Comparison of Single-piece and Welded Orthogrid-Stiffened Cylinder Buckling Responses}

As mentioned earlier, to better assess the effects of having welded joints, the acreage of design of STA8.1 was based on an 8-ft diameter test article with weld lands that was previously tested by SBKF. That is, STA8.1 and the welded test article, known as TA09, had very similar stiffener spacing, thickness, and height as reported in Table 1. Though the geometry was similar, STA8.1 and TA09 were made out of different aluminum alloys. TA09 was an assembly of three Al-Li 2195 orthogrid-stiffened panels that were welded together using the friction stir weld process. The test article contained three weld lands spaced 120-degrees apart. The OML of TA09 was also structured-light scanned, and the radial imperfections from the manufacturing process are presented in Fig. 15.

An interesting feature of the TA09 geometric imperfections was the distinct signature left behind from the welding process. As seen in Fig. 15, there were localized areas of inward deformation, the blue regions, located at each weld land location at $60^{\circ}, 180^{\circ}$, and $300^{\circ}$. These areas were due to shrinkage caused by the friction stir welding process. TA09 had a minimum inward radial displacement of 0.138-in, and the maximum outward radial displacement was 0.104-in; a total amplitude of 0.242-in. The STA8.1 geometric imperfection plot, Fig. 4, does not have defined, localized areas of inward imperfections. For STA8.1 the maximum outward displacement was 0.056-in., and the minimum inward displacement is 0.037 -in; total amplitude of 0.093 . The TA09 imperfection amplitude was more than double than the imperfection amplitude of STA8.1.

An analytical comparison can be made between STA8.1 and TA09 to assess the effects of the geometric imperfections and weld lands because the acreage designs are essentially the same. To start, the nonlinear transient buckling load for a uniform, uninterrupted acreage without weld lands, similar to STA8.1, with no geometric imperfections is $738,000 \mathrm{lb}$. The nonlinear transient FEM response with as-designed geometry with weld lands and the TA09 measured geometric imperfections is $509,000 \mathrm{lb}$. These results imply that the combination of the weld lands and the geometric imperfections caused by the welding process reduced the load carrying capability by $31 \%$.

To assess the effects of the weld lands alone, a nonlinear transient analysis was completed using a FEM containing TA09 nominal geometry with weld lands and no geometric imperfections. The analysis resulted in a buckling load $585,000 \mathrm{lbs}$. This is compared to the 738,000 lb. buckling load calculated from the nonlinear transient buckling load of TA09 with a uniform stiffness, i.e. without weld lands, which indicates that $21 \%$ of the loss of load carrying capability was due to the weld lands. 
The effect of imperfections without the influence of weld lands can be evaluated by mapping the TA09 geometric imperfection on to a model of TA09 without weld lands. A nonlinear transient analysis of this model resulted in a buckling load of 646,000 lb. Comparing this value to the perfect, uniform stiffness nonlinear transient buckling load of 738,000 lb., the geometric imperfections contributed to an approximately $12 \%$ of the reduction in load carrying capability. Therefore, it can be concluded that weld lands are the primary contributor to the reduction in buckling load.

To understand the effects of geometric imperfections on STA8.1, the nonlinear transient analysis buckling load of STA8.1, with as-designed geometry and no geometric imperfections is $720,000 \mathrm{lb}$. was calculated. This value can be compared to the pretest prediction buckling load determine from a nonlinear transient FEM with as-designed geometry with the measured STA8.1 geometric imperfections, 697,000 lb. These results show that the measured geometric imperfections reduced the buckling load for this specific acreage design by 3\%. All loads are summarized in Table 2 .

Based on this analysis, it can be seen that the contributions of the radial imperfections and the stiffness discontinuity that result from the presence of weld lands decreases load carrying capability significantly. Considering the $31 \%$ reduction in buckling load due to the weld lands and the radial imperfections due to welding process, and the $3 \%$ reduction in buckling load caused by radial imperfections from the seamless cylinder manufacturing; it can be concluded that a $28 \%$ increase in load carrying capability can be achieved with this acreage design using seamless manufacturing techniques. Due to the unknown variability in the as-built geometry and as-tested configuration for TA09, data from STA8.1 and TA09 tests was not used for direct comparison.

\section{Concluding Remarks}

To demonstrate the efficiency of cylinders with no weld lands, a seamless buckling-critical 8-ft-diameter orthogridstiffened cylinder, STA8.1, was tested to failure. The test article presented in this paper was manufactured using a flow-forming process to create a grid-stiffened cylinder with no weld lands. After a series of model refinements backed by observation, the failure load predicted by the model with as-built geometry with uniform compression was within $1.5 \%$ of the measured test load. It was determined that the variable with greatest influence on the test and analysis correlation was the as-built geometry. Furthermore, the effects of non-uniform loading did improve the predicted response, but the load variation was within the tolerance of the load cells. In addition, while the separate tension and compression moduli better aligned the FEM global buckling response to the test data, this model adjustment did not consistently improve correlation at the local level. This paper also included an assessment of the potential effects that weld lands and welding imperfections have on the stability of a grid-stiffened cylinder. It was determined that the presence of these two features can lower the load carrying capability of the considered cylinder by $28 \%$. The results from the test to failure of STA8.1 will advance the SBKF goal of demonstrating the potential of the seamless cylinder manufacturing to build more efficient buckling-critical structures by eliminating weld lands.

\section{Acknowledgements}

This work was conducted as part of the NASA Engineering and Safety Center (NESC) Shell Buckling Knockdown Factor Project, NESC assessment number 07-010-E. The large-scale testing was performed by the Structural Strength Test Group (ET30) at MSFC.

\section{References}

${ }^{1}$ Hilburger M.W., "Developing the Next Generation Shell Buckling Design Factors and Technologies," Proceedings of the 53rd AIAA/ASME/ASCE/AHS/ASC Structures, Structural Dynamics and Materials Conference, AIAA paper no. 2012-1686, Honolulu, HI, April 2012.

${ }^{2}$ Anonymous, "Metallic Material Properties Development and Standardization," MMPDS-10, April 2015.

${ }^{3}$ Hilburger, M. W., Haynie, W. T., Lovejoy, A. E., Roberts, M. G., Norris, J. P., Waters, W. A., and Herring, H. M., "Subscale and Full-Scale Testing of Buckling-Critical Launch Vehicle Shell Structures," Proceedings of the 53rd AIAA/ASME/ASCE/AHS/ASC Structures, Structural Dynamics and Materials Conference, AIAA paper no. 2012-1688, Honolulu, HI, April 2012.

${ }^{4}$ Abaqus/Standard 2016, Software Package, SIMULIA, Rising Sun Mills, Providence, RI, 2016.

${ }^{5}$ Hilburger, M. W., Lindell, M. C. Lovejoy, A. E., Haynie, W. T., Waters, W. A., Jr., Gardner, N. W., and Matarese, R. A., "Buckling Analysis and Test Results from Selected 8-Foot-Diameter Integrally-Stiffened Al-Li Cylinder Test Articles", NASA TM-2017-000000, 2017. (In preparation) 
Table 1. STA8.1 nominal geometry and as-built geometry model inputs.

\begin{tabular}{|l|c|c|}
\hline \multicolumn{1}{|c|}{ Geometry } & Nominal & As-built average \\
\hline Skin thickness & $0.070 \mathrm{in.}$ & $0.0753 \mathrm{in}$. \\
Stiffener height & $0.500 \mathrm{in.}$ & $0.500 \mathrm{in.}$ \\
Stiffener thickness & $0.065 \mathrm{in.}$ & $0.070 \mathrm{in}$. \\
Transition thickness & $0.135 \mathrm{in.}$ & $0.139 \mathrm{in}$. \\
End thickness & $0.200 \mathrm{in.}$ & $0.206 \mathrm{in}$. \\
\hline
\end{tabular}

Table 2. Summary of analysis buckling loads from weld land geometric imperfection sensitivity study.

\begin{tabular}{|l|c|c|}
\hline \multicolumn{1}{|c|}{ Analysis Details } & STA8.1 & TA09 \\
\hline Nonlinear transient w/o geometric imperfections w/o weld lands & $720,000 \mathrm{lb}$ & $738,000 \mathrm{lb}$ \\
Nonlinear transient w/o geometric imperfections w/ weld lands & - & $585,000 \mathrm{lb}$ \\
Nonlinear transient w/ geometric imperfections w/o weld lands & $697,000 \mathrm{lb}$ & $646,000 \mathrm{lb}$ \\
Nonlinear transient w/ geometric imperfections w weld lands & - & $509,000 \mathrm{lb}$ \\
\hline
\end{tabular}

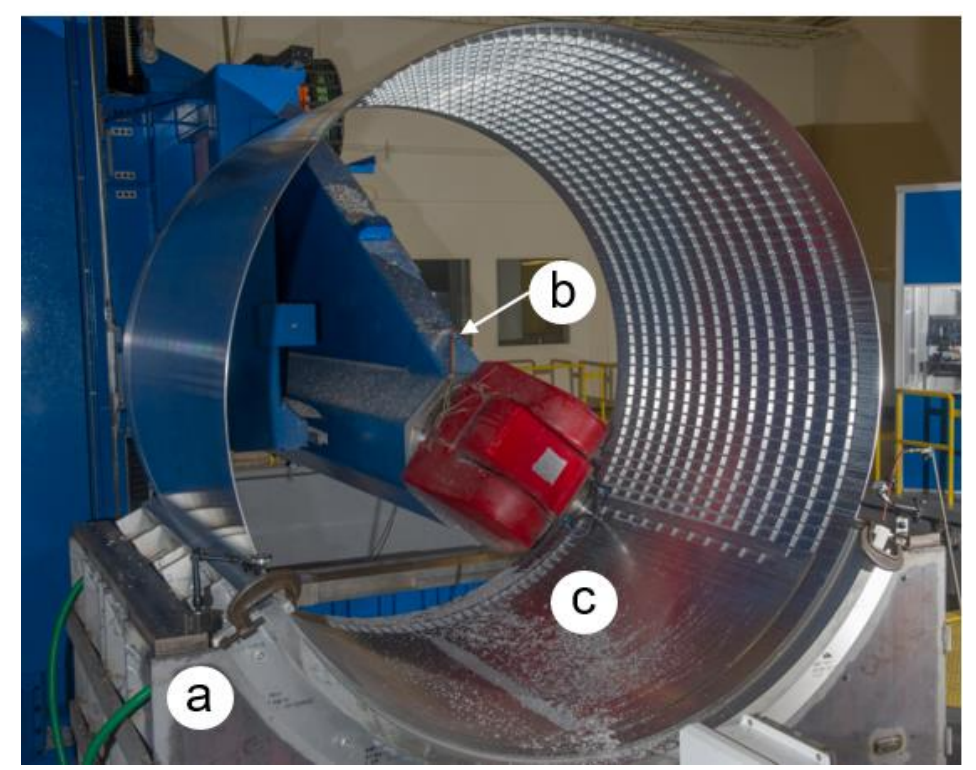

Figure 1. STA8.1 being machined on the 7-axis milling machine. a) vacuum chuck; b) 7-axis milling machine; c) test article 


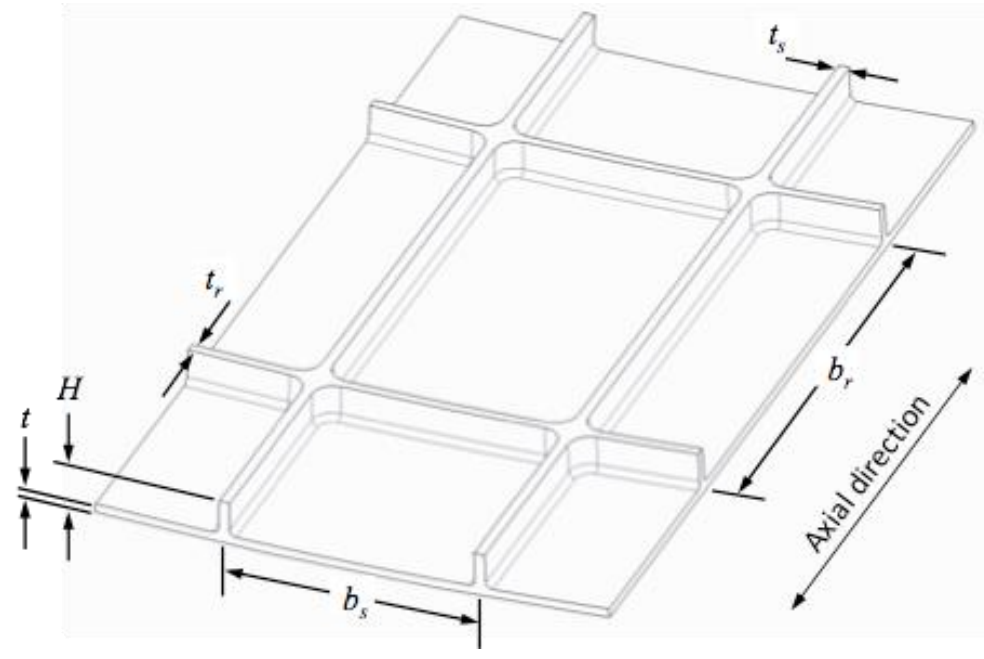

Figure 2. Orthogrid acreage geometry definition.

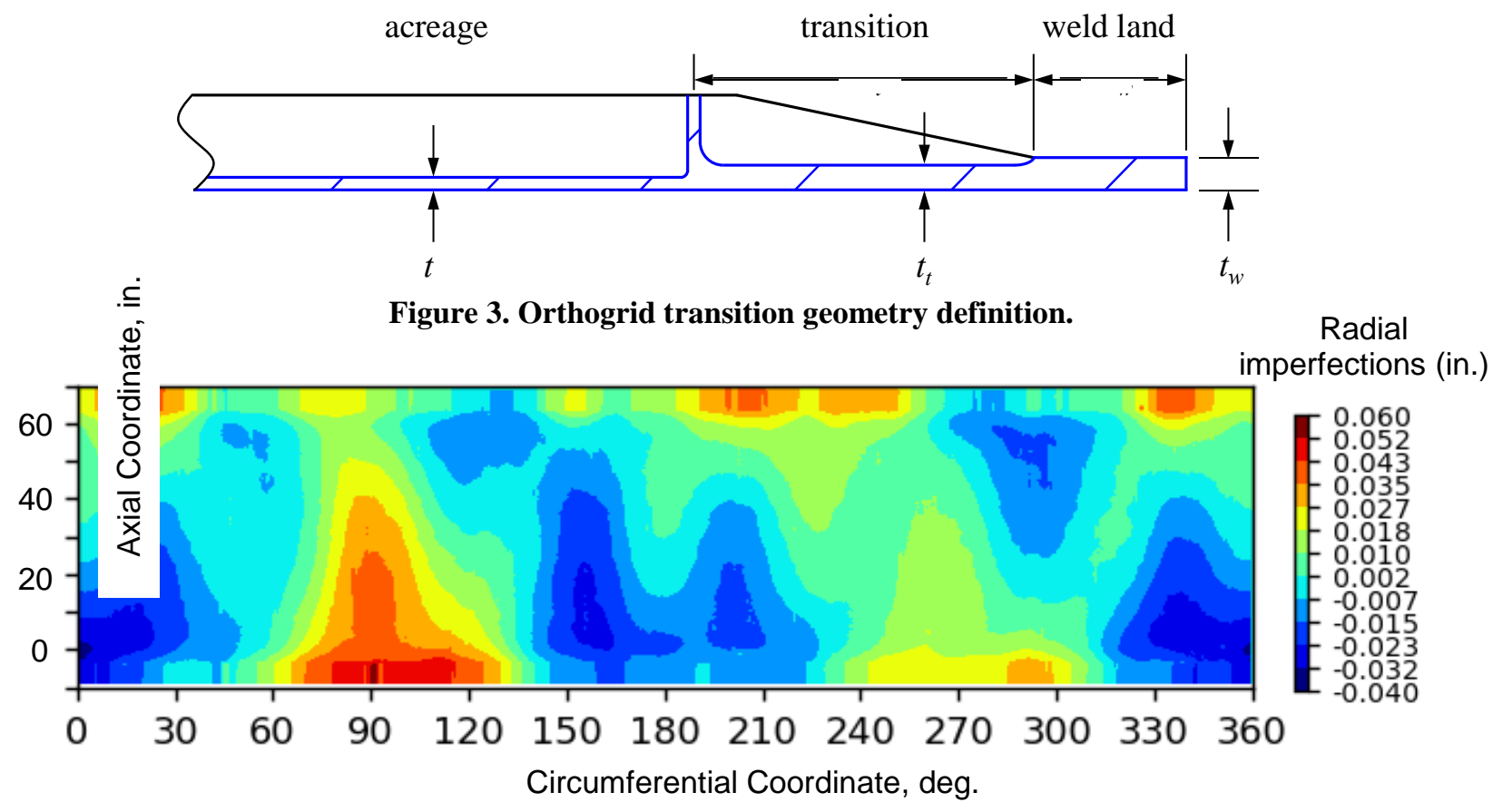

Figure 4. Test article STA8.1 measured radial imperfections. 


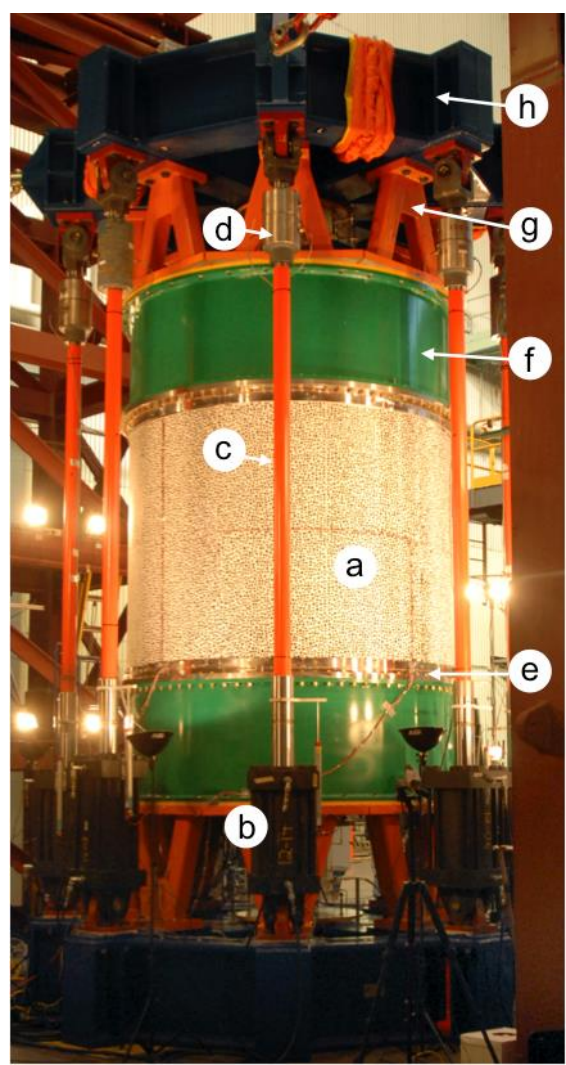

Figure 5. Eight-foot-diameter shell buckling test facility at MSFC: a) test-article assembly; b) hydraulic actuator; c) loading rod; d) load cell; e) interface ring; f) transition section; g) load strut; and $h$ ) loading spider.

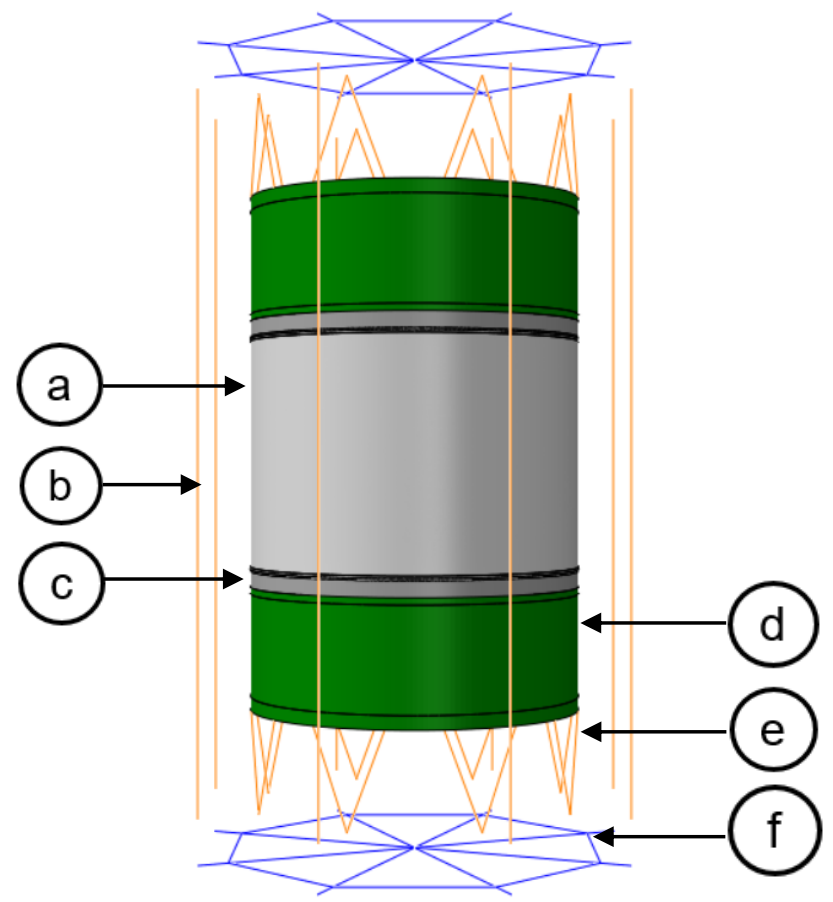

Figure 6. The STA8.1 test assembly finite-element model: a) test-article assembly, b) loading rod, c) interface ring, d) transition section, e) load strut, and f) loading spider. 

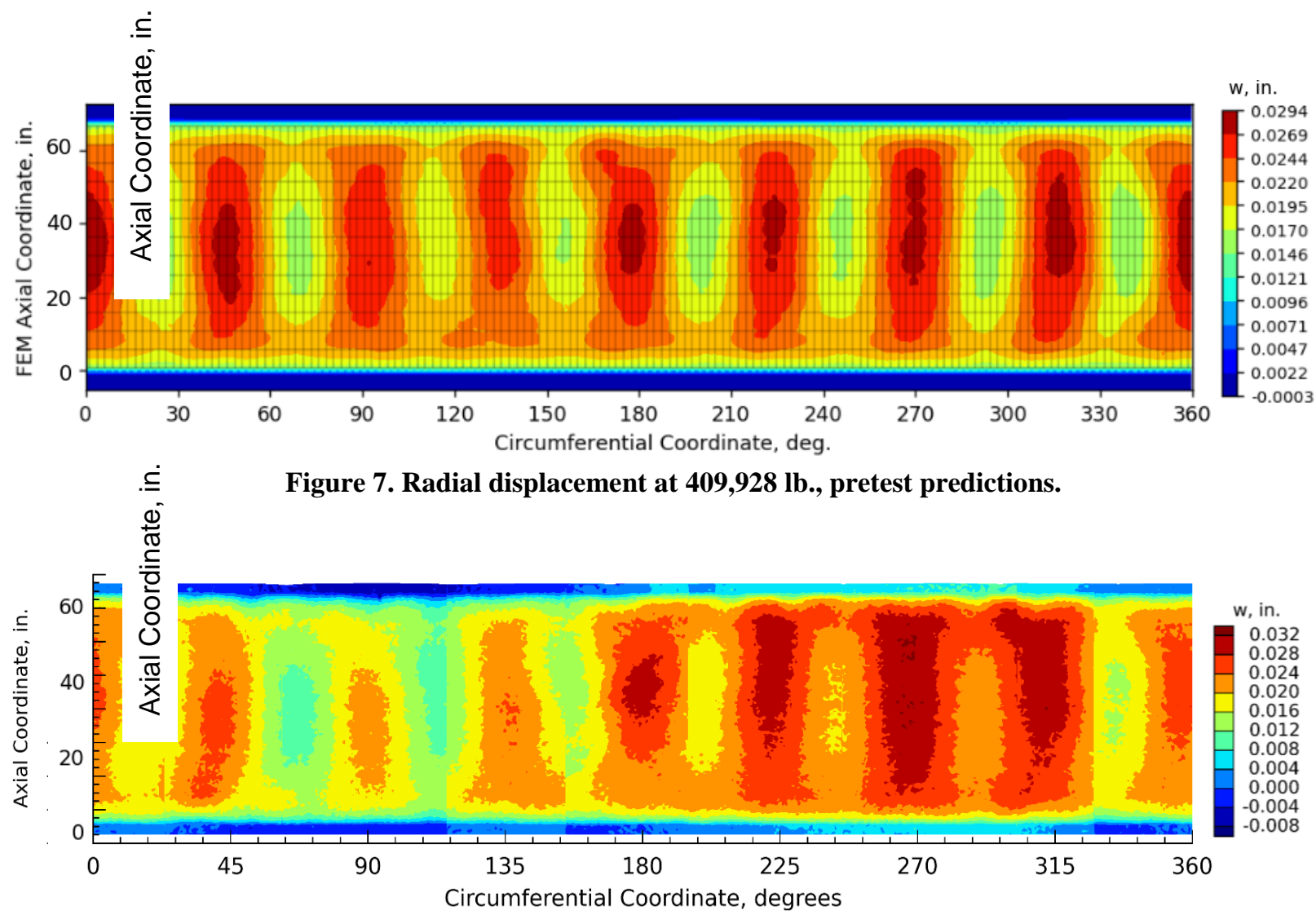

Figure 8. Radial displacement at 409,928 lb., test. 


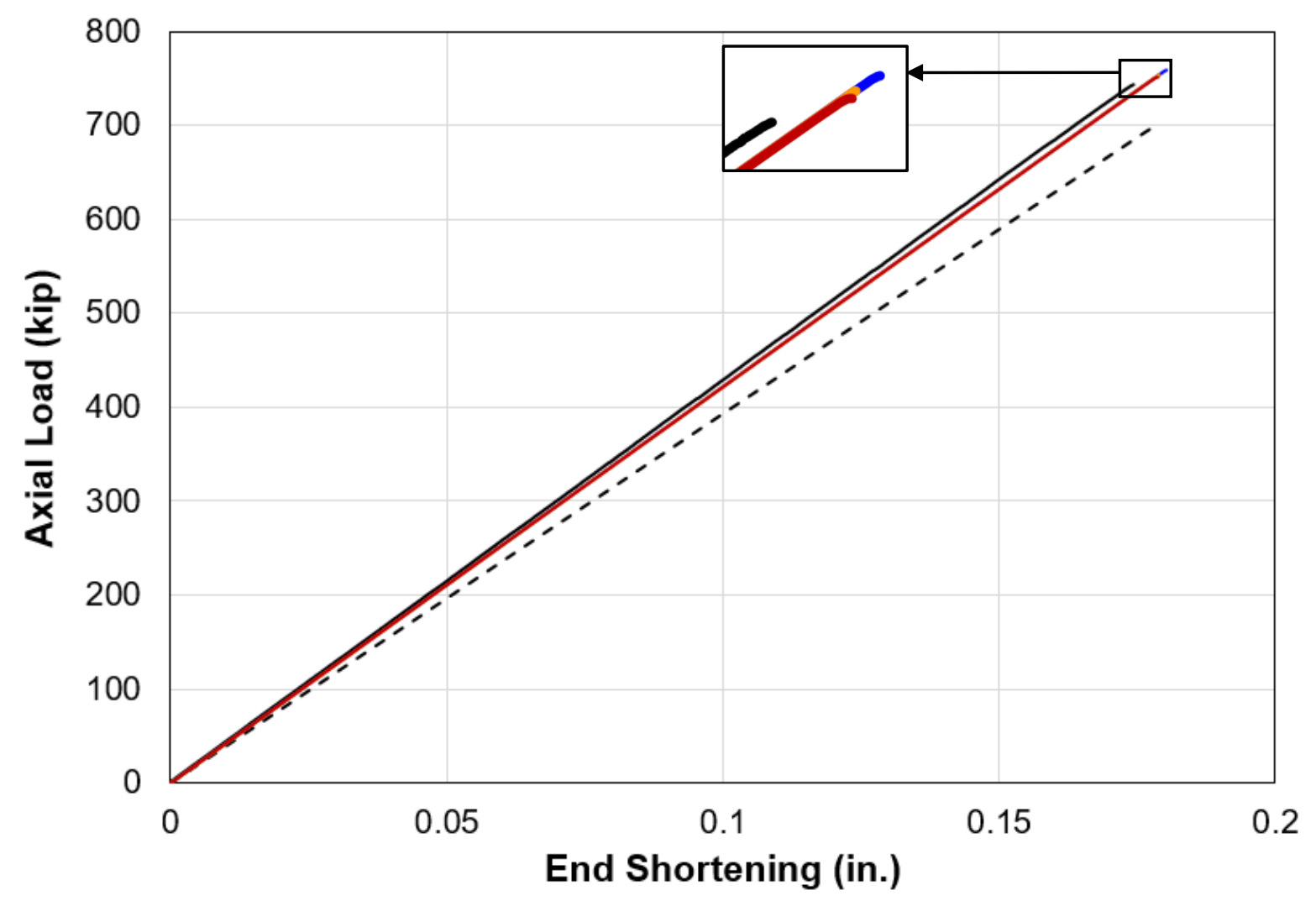

- Test

- - Pretest predictions

—As-built geometry with isotropic material properties

— As-built geometry with isotropic material properties and $0.2 \%$ moment

—As-built geometry with orthotropic material properties

Figure 8. Load vs. average axial displacement for the final load sequence to failure including test results, pretest predictions using as-designed geometry and isotropic material properties, as-built geometry with isotropic material properties, as-built geometry with isotropic material properties and $0.2 \%$ loading moment, as-built geometry with orthotropic material properties. 

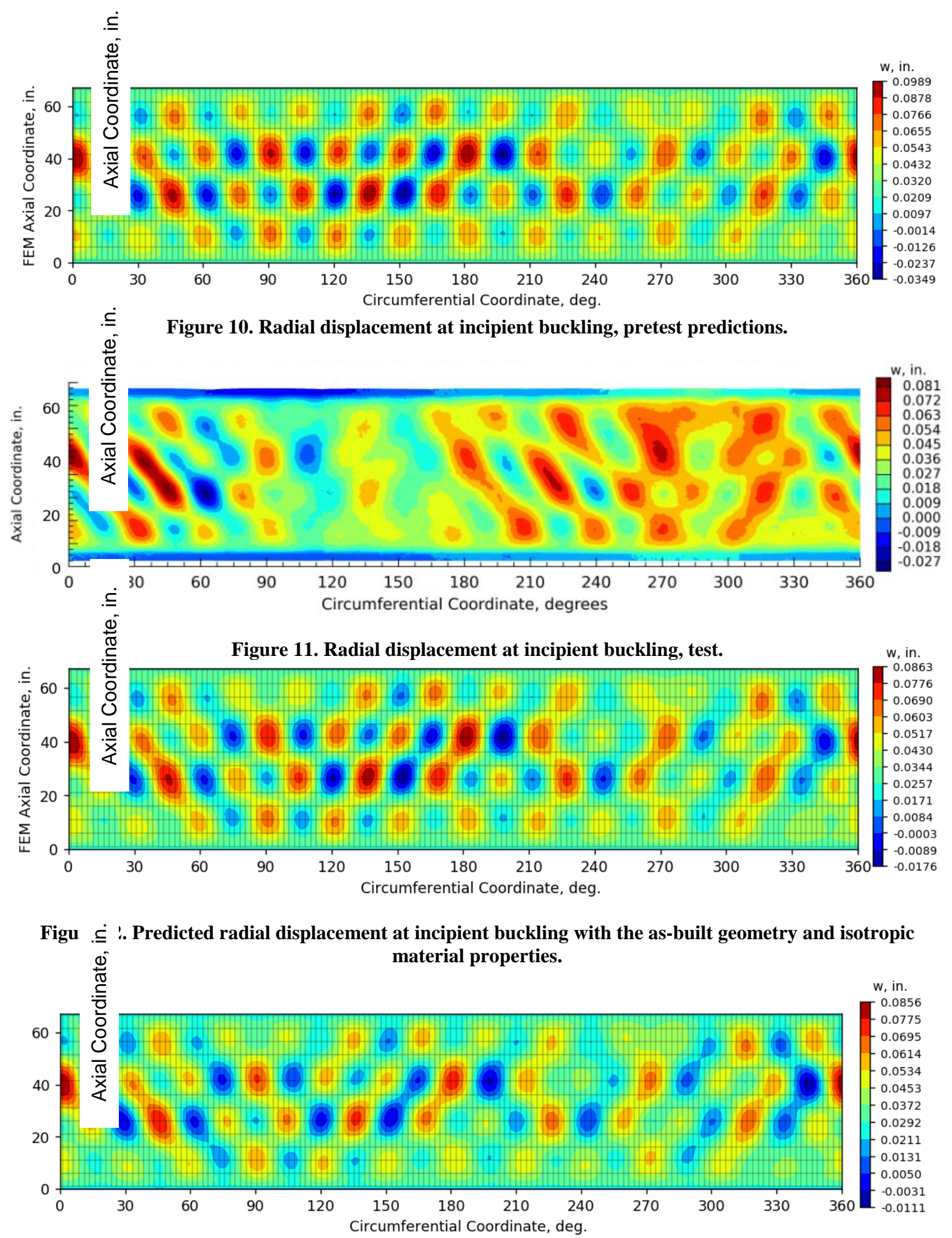

Figure 13. Predicted radial displacement at incipient buckling with the as-built geometry, isotropic material properties, and a $0.2 \%$ bending moment due to applied load variation. 


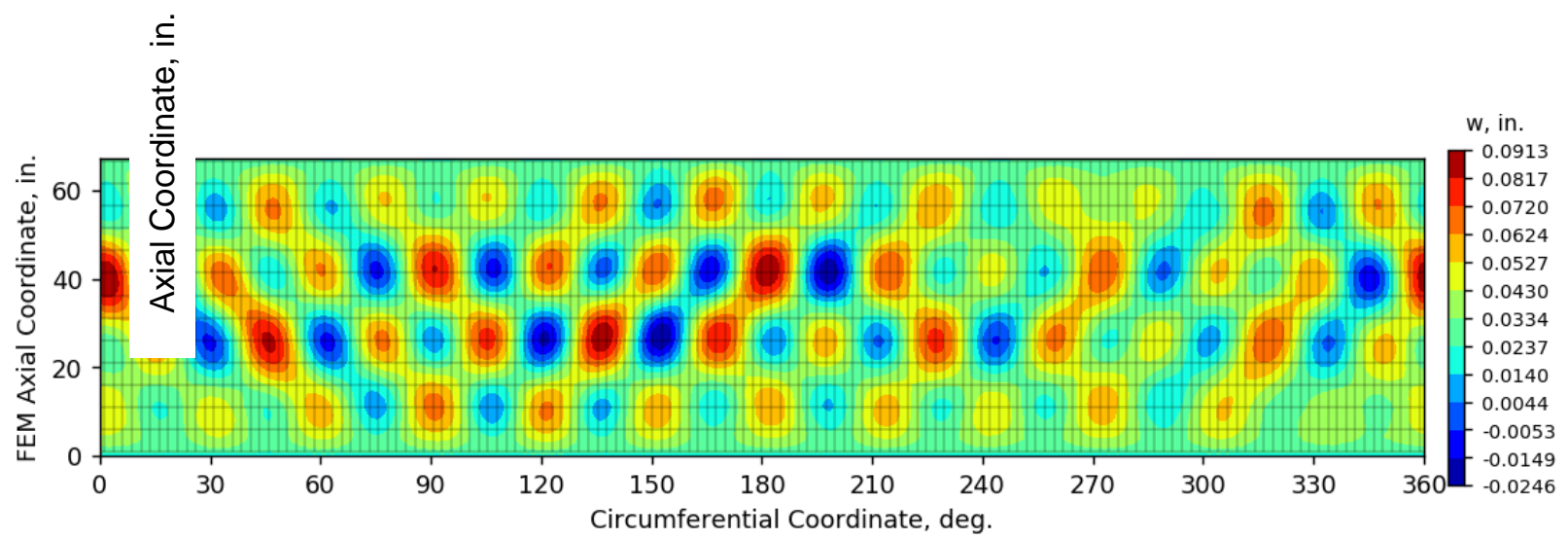

Figure - Tredicted radial displacement at incipient buckling with the as-built geometry, orthotropic

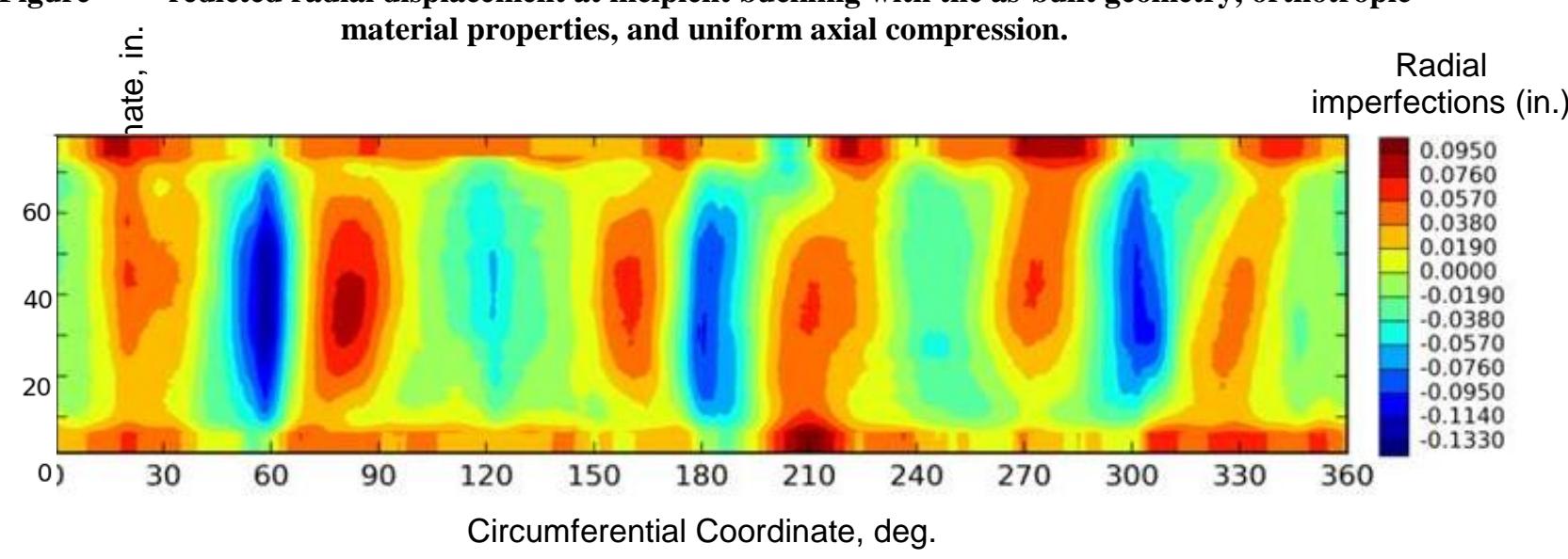

Figure 15. TA09 radial imperfections. 